\title{
Electroacupuncture promotes the recovery of rats with spinal cord injury by suppressing the Notch signaling pathway via the H19/ EZH2 axis
}

\author{
Xin Geng", Yanghong Zou", Shipeng Li, Renli Qi, Cong Jing, Xiangqian Ding, Jinghui Li, Hualin Yu \\ Second Department of Neurosurgery, First Affiliated Hospital of Kunming Medical University, Kunming, China \\ Contributions: (I) Conception and design: $\mathrm{H} \mathrm{Yu,} \mathrm{J} \mathrm{Li;} \mathrm{(II)} \mathrm{Administrative} \mathrm{support:} \mathrm{All} \mathrm{authors;} \mathrm{(III)} \mathrm{Provision} \mathrm{of} \mathrm{study} \mathrm{materials} \mathrm{or} \mathrm{patients:} \mathrm{H}$ Yu, J Li, \\ X Geng, Y Zou; (IV) Collection and assembly of data: X Geng, Y Zou, S Li; (V) Data analysis and interpretation: X Geng, R Qi, C Jing, X Ding; (VI) \\ Manuscript writing: All authors; (VII) Final approval of manuscript: All authors. \\ \#These authors contributed equally to this work. \\ Correspondence to: Hualin Yu, MD; Jinghui Li, MD. Second Department of Neurosurgery, First Affiliated Hospital of Kunming Medical University, \\ No. 295 Xichang Road, Kunming 650032, China. Email: yuhualin225@126.com; km_lih@126.com.
}

Background: Spinal cord injury (SCI) is a life-changing event with an extremely poor prognosis. In our preliminary studies, electroacupuncture (EA) was found to promote the repair of SCI, which was closely related to the Notch signaling pathway. Therefore, in the present study, we hypothesized that EA protects against SCI by inhibiting the Notch signaling pathway and sought to investigate the underlying molecular mechanisms.

Methods: Rat and cell models of SCI were established. The expression of long non-coding RNA H19 was measured by real-time quantitative polymerase chain reaction. The expression levels of EZH2, Notch1, Notch3, Notch4, Hes1, and PS1 protein were measured by western blot. Cell apoptosis and viability were analyzed using flow cytometry and Cell Counting Kit- 8 assays, respectively. The expressions of glial fibrillary acidic protein (GFAP) and nestin were detected by immunofluorescence staining.

Results: The expressions of H19, EZH2, and GFAP were significantly increased after SCI but were inhibited by EA; in contrast, nestin expression was significantly decreased by SCI but was restored by EA. Moreover, oxygen-glucose deprivation (OGD) treatment elevated the expression of H19, EZH2, and Notchrelated factors as well as apoptosis in PC-12 cells, while suppressing cell viability. Suppressing H19 alleviated the effects of OGD on cell viability and apoptosis, and inhibited the expression of EZH2 and Notch-related factors expression; these effects were reversed by EZH2 overexpression. Finally, EA promoted the recovery of SCI rats and neural stem cell (NSC) proliferation by inhibiting the Notch signaling pathway, which was reversed by $\mathrm{H} 19$ overexpression.

Conclusions: Our results demonstrated that EA promotes the recovery of SCI rats and increases the proliferation and differentiation of NSCs by suppressing the Notch signaling pathway via modulating the H19/EZH2 axis.

Keywords: Electroacupuncture (EA); spinal cord injury (SCI); lncRNA H19; EZH2; Notch signaling pathway

Submitted Feb 05, 2021. Accepted for publication Apr 17, 2021.

doi: $10.21037 / \mathrm{atm}-21-1526$

View this article at: http://dx.doi.org/10.21037/atm-21-1526 


\section{Introduction}

With its continuously increasing incidence, spinal cord injury (SCI) has become a global burden (1). SCI is the most common condition resulting from damage to the spinal cord. Patients with SCI experience central neuropathic pain and skeletal muscle dystrophy, as well as loss of force, fiber cross-sectional area, and endurance (2-5). In the primary injury, red blood cells, myelin, subcellular debris, and necrotic and apoptotic neurons damaged by the traumatic injury are featured prominently in the lesion epicenter, leading to secondary injury (6). In clinical practice, surgical decompression, blood pressure augmentation, and i.v. methylprednisolone would protect nerve cell apoptosis (7). Secondary injury mainly includes inflammation, extravasation of infiltrating leukocytes, and proliferation and morphological changes in glial cells (6). Confronting the axon with a combination of chronic astrocytosis and extracellular matrix-associated inhibitors that collectively constitute the chronic "scar" (8), suggesting that inhibition of glial cells would promote the recovery of locomotor in SCI. Previous studies have shown that electroacupuncture (EA) is able to inhibit neuronal apoptosis, improve the spinal cord microenvironment, and accelerate edema reduction and neural function repair (9-11). In our preliminary study, we demonstrated that EA promotes the repair of SCI in rats, improves neural stem cell (NSC) proliferation, and inhibits the differentiation of NSCs into astrocytes (12), which suggested that EA may ameliorate the function of the injured nervous system by stimulating NSC proliferation $(13,14)$. However, the molecular mechanism by which EA promotes the repair of SCI has yet to be illuminated.

The Notch signaling pathway is an evolutionarily conserved signaling pathway that participates in the proliferation and maintenance of NSCs and the determination of their daughter cells' fate, as well as cell migration, differentiation, and apoptosis $(15,16)$. The Notch signaling pathway is activated in some human diseases, including atherosclerosis, colorectal cancer, and SCI (17-19). It has been reported that inhibition of the Notch signaling pathway may play a role in promoting SCI repair through inducing NSC differentiation, and decreasing neuroinflammation and neuronal apoptosis $(20,21)$. Interestingly, a previous study found that EA inhibits the expression of proinflammatory cytokines and Notch signaling pathway-related factors (12), suggesting that EA-induced suppression of the Notch signaling pathway contributes to alleviating SCI. Thus, further research of the molecular mechanisms underlying the inhibitive effects of EA on the Notch signaling pathway may provide a basis for adjunctive EA therapy in SCI.

Enhancer of zeste homolog 2 (EZH2), a histone methyltransferase, plays an important role in cell differentiation, inflammation, myofibroblast transformation, and tissue fibrosis (22-24). Notably, Wasson et al. demonstrated that EZH2 acts as a regulator of the Notch signaling pathway in human cholangiocarcinoma and systemic sclerosis, while EZH2 inhibitor (GSK126) decreases myofibroblast activation and cholangiocarcinoma cell growth via Notch signaling pathway inhibition $(25,26)$. Nevertheless, the details of the Notch signaling pathway's function in SCI remain elusive.

There is increasing evidence that long non-coding RNAs (lncRNAs) participate in numerous cellular processes, including proliferation, differentiation, and apoptosis, and play an indispensable role in several physiologic and pathologic processes including the pathogenesis of SCI $(27,28)$. Several such lncRNAs have been identified and characterized (29). For instance, lncRNA H19, which has a molecular weight of $2.3 \mathrm{~kb}$, is highly expressed in SCI, diabetes mellitus, and rheumatoid arthritis. It contributes to neuronal cell apoptosis by regulating let-7b, Wnt, and the Notch signaling pathway (29-33). H19 has also been found to regulate EZH2 expression in some abnormal cells and tissues $(34,35)$, suggesting that it may be involved in the repair of SCI via its association with EZH2 expression.

EA was observed to inhibit the Notch signaling pathwayrelated factors in SCI. However, whether H19 is involved in the aberrant expression of EZH2 or the activation of Notch signaling pathway in SCI remains unknown. In this study, we investigated the expression and function of H19, EZH2, and Notch signaling pathway-related factors in SCI, and explored the relationships among EA, H19, EZH2, and the Notch signaling pathway, in an effort to identify a potential target for SCI therapy. We present the following article in accordance with the ARRIVE reporting checklist (available at http://dx.doi.org/10.21037/atm-21-1526).

\section{Methods}

\section{Animals}

Adult male Sprague Dawley rats $(\mathrm{n}=40 ; 6$ to 7 weeks old; weight, 300-350 g) were supplied by the Experimental Animal Center of Kunming Medical University (Kunming, 
China). All rats were housed under a 12-hour light/dark cycle at room temperature with ad libitum access to food and water. All animal experiments were performed in accordance with the guidelines for animal care and approved by the Institutional Animal Care and Use Committee at Kunming Medical University (No. 2020-158).

\section{SCI rat model establishment and EA treatment}

An SCI rat model was established following a method described in our previous study (12). Briefly, the spinal cords of rats were exposed and clamped for 60 seconds $(36,37)$. In the SCI+EA group $(n=5)$, SCI rats were subjected to $2 \mathrm{~Hz}$ stimulation for 30 minutes with the output voltage set at $2 \mathrm{~V}$. EA was administered once a day, as described in previous study (12). Untreated rats were used as the control group ( $\mathrm{n}=5$ ).

\section{Cell culture and oxygen-glucose deprivation (OGD) model}

PC-12 cells were obtained from Beijing Beina Chuanglian Biotechnology Institute (Beijing, China). The cells were cultured in Roswell Park Memorial Institute (RPMI) 1640 Medium (Sigma-Aldrich, St. Louis, MO, USA) containing 10\% fetal bovine serum (FBS; HyClone, Logan, UT, USA), $100 \mathrm{mg} / \mathrm{mL}$ streptomycin, and $100 \mathrm{U} / \mathrm{mL}$ penicillin at $37^{\circ} \mathrm{C}$ in a humidified incubator set to $5 \% \mathrm{CO}_{2}$. The culture medium was replaced with fresh medium every other day.

A PC-12 OGD model was established as previously described (38). Briefly, the cell medium was replaced by glucose-free medium, which was pretreated with $95 \%$ $\mathrm{N}_{2}$ in an incubator with $5 \% \mathrm{CO}_{2}$ at $37{ }^{\circ} \mathrm{C}$ for 30 minutes. Next, the PC-12 cells were immediately placed in a sealed chamber containing $95 \% \mathrm{~N}_{2}$ with $5 \% \mathrm{CO}_{2}$ for 12 hours at $37^{\circ} \mathrm{C}$. Afterward, the cells were taken out and cultured in normal medium for 24 hours at $37^{\circ} \mathrm{C}$ in an incubator with $5 \% \mathrm{CO}_{2}$. Cells cultured in the same medium without OGD treatment were used as negative controls (NCs).

\section{Real-time quantitative polymerase chain reaction}

Total RNA was isolated from spinal cord tissues and PC-12 cells using TRIzol (Takara, Biotechnology Co., Ltd., Dalian, Liaoning Province, China). Real-time quantitative polymerase chain reaction (RT-qPCR) was performed using SYBR Green qPCR Master Mix (Takara, Biotechnology Co., Ltd., Dalian, China). Measurement of the expression levels of $\mathrm{H} 19$ was carried out with the
ABI Prism 7300 Sequence Detection System (Applied Biosystems, USA). Special primers were designed and synthesized by Sangon Biotech (Shanghai, China). For each sample, at least 3 parallel reactions were carried out. The primer sequences were as follows: H19 forward, 5'-TACAACCACTGCACTACCTG-3' and reverse, 5'-TGGAATGCTTGAAGGCTGCT-3'; and $\beta$-Actin forward, 5'-GGCGACGAGGCCCAGA-3' and reverse, 5'-CGATTTCCCGCTCGGC-3'. The $2^{-\Delta \Delta C T}$ method was employed for data analysis (39), and $\beta$-Actin was chosen as an internal control.

\section{Western blot assay}

Proteins were extracted from rat spinal cords and PC12 cells with RIPA buffer (Beyotime Biotechnology, Shanghai, China). The protein concentration was determined according to the standard protocols of BCA protein assay kits (Sangon Biotech, Shanghai, China). Protein samples $(40 \mu \mathrm{g})$ were separated by $10 \%$ sodium dodecyl sulphate-polyacrylamide gel electrophoresis (SDS-PAGE) and then transferred to polyvinylidene difluoride (PVDF) membranes. After being blocked in $5 \%$ skim milk for 1 hour at room temperature, the membranes were incubated with primary antibodies against EZH2 (1:1,000; Abcam, Cambridge, MA, USA), Notch1 (1:1,000; Abcam, Cambridge, MA, USA), Notch3 (1:1,000; Abcam, Cambridge, MA, USA), Notch4 (1:1,000; Abcam, Cambridge, MA, USA), PS-1 (1:2,000; Abcam, Cambridge, MA, USA), Hes1 (1:1,000; Abcam, Cambridge, MA, USA), or $\beta$-Actin $(1: 2,000$; Abcam, Cambridge, MA, USA). After incubation at $4{ }^{\circ} \mathrm{C}$ overnight, The membranes were incubated with horseradish peroxidase-conjugated secondary antibodies for 2 hours at room temperature. The immunoreactive bands were visualized using an enhanced chemiluminescence reagent (Beyotime, Beijing, China). Each band was semi-quantified using ImageJ (version 1.47; National Institutes of Health, Bethesda, MD, USA).

\section{Cell viability analysis}

Cell viability was detected using a Cell Counting Kit-8 assay (CCK-8; Sigma, MO, USA) according to the manufacturer's instructions. PC-12 cells were seeded into 96-well plates at a density of $1 \times 10^{5}$ cells $/ \mathrm{mL}(100 \mu \mathrm{L})$ and cultured 24 hours after. After treatment, $10 \mu \mathrm{L}$ CCK-8 solution was added to each well, and the cells were incubated at $37^{\circ} \mathrm{C}$ for 4 hours. 
The optical density (OD) was measured at $450 \mathrm{~nm}$ with a micrometer reader (BioTek Instruments Inc).

\section{Apoptosis assay}

PC-12 cells were detached with trypsin/EDTA (ethylenediaminetetraacetic acid), collected, and centrifuged at $178 \times \mathrm{g}$ at $4{ }^{\circ} \mathrm{C}$ for 5 minutes, and the supernatant was removed. The cells were washed with cool phosphate buffer solution and then centrifuged at $178 \times \mathrm{g}$ for 5 minutes, after which the supernatant was discarded. PC-12 cell apoptosis was detected using an Annexin-V-fluorescein isothiocyanate/ propidium iodide (FITC/PI) kit (CA1020; Solarbio, Beijing, China). The rates of PC-12 cell apoptosis were measured with a flow cytometer (BD Biosciences, Franklin Lakes, NJ, USA) and analyzed with FlowJo version 10 (FlowJo LLC).

\section{Lentiviral construction and transduction for transgene expression}

Lentiviral injection was performed as described by Ji et al. (40). Briefly, we used reverse transcription (RT) PCR to amplify the coding sequence of H19, which was ligated into the pGV208 plasmid (Shanghai Gene Chem) to express H19. At 3 days after surgery, lentiviral vectors, lenti-H19 and lenti-control, were injected into the epicenter of rats' injured spinal cords with a 5 -mL Hamilton syringe at a depth of 0.5 and $1 \mathrm{~mm}(1 \mathrm{~mL}$ at each depth) and a rate of $200 \mathrm{~nL} /$ minute. After the injection, the pipettes were left in place for 1 minute and then slowly withdrawn. The rats were sacrificed at 14 days after SCI.

\section{Immunofluorescence staining}

For immunofluorescence staining, 10 - $\mu \mathrm{m}$-thick sections of spinal cord tissue were fixed in $4 \%$ paraformaldehyde at $4{ }^{\circ} \mathrm{C}$. The spinal cord tissues were incubated with blocking solution $(0.2 \%$ Triton $\mathrm{X}-100(\mathrm{v} / \mathrm{v})$ and $5 \%$ bovine serum albumin (v/v) at room temperature for 1 hour, and then incubated at $4^{\circ} \mathrm{C}$ overnight with the respective specific antibodies against glial fibrillary acidic protein (GFAP; 1:1,000; Abcam, Cambridge, MA, USA) and nestin (1:200; Abcam, Cambridge, MA, USA). After rinsing, the sections were incubated with Alexa Fluor 555 (1:500; Abcam, Cambridge, MA, USA) anti-rabbit IgG for 1 hour. Nuclei were counterstained with 4',6-diamidino-2-phenylindole (DAPI). A Nikon Eclipse 80i microscope (Nikon, Tokyo, Japan) was used to capture fluorescence images.

\section{Statistical analysis}

All experimental data were expressed as mean \pm standard deviation (SD). Comparisons between 2 groups were performed using two-tailed Student's $t$-tests, and multigroup comparisons were performed using one-way analysis of variance (ANOVA) with Tukey's post-hoc test. $\mathrm{P}<0.05$ was considered to be statistically significant. All analyses were performed in SPSS 19.0(SPSS Inc., Chicago, IL, USA).

\section{Results}

\section{EA inbibits the expression of H19 and EZH2 in SCI rats}

EA was previously reported to repair SCI and promote the proliferation of endogenous NSCs, which play critical roles in SCI (12). Therefore, we explored whether EA could alleviate SCI in a rat model. Immunofluorescence staining results confirmed that EA significantly increased the levels of nestin protein while decreasing those of GFAP protein (Figure 1A), indicating that EA significantly increases NSC proliferation and inhibits NSC differentiation into astrocytes. Interestingly, a recent study reported the upregulation of H19 in SCI rats (29), and $\mathrm{H} 19$ has also been shown to regulate EZH2 expression in some abnormal cells and tissues $(34,35)$. Therefore, we assessed H19 mRNA and EZH2 protein expression in the spinal cord tissues of SCI rats at 14 days after EA by performing RT-qPCR and western blot, respectively. As shown in Figure $1 B, C$, compared to those in the sham group, the levels of $\mathrm{H} 19$ mRNA and EZH2 protein expression were remarkably upregulated in the SCI rats; however, they were significantly downregulated by EA treatment. These results suggested that EA inhibited the expression of $\mathrm{H} 19$ and EZH2 in SCI rats.

\section{Suppression of H19 inbibits the Notch signaling pathway and OGD-induced injury in PC-12 cells}

PC-12 cells were exposed to OGD for 24 hours. Compared to the NC group, OGD-treated cells exhibited significantly increased H19 expression (Figure 2A). OGD also markedly increased the proportion of apoptotic cells (Figure $2 B$ ) and inhibited cell viability (Figure 2C). Moreover, the protein expression levels of Notch-related factors (Notch1, Notch3, Notch4, Hes1, and PS1) were significantly increased in the OGD group (Figure 2D). Subsequently, to further study the effects of H19, we knocked down H19 expression through transfection with H19 small interfering RNA (si-H19). The suppression of $\mathrm{H} 19$ significantly attenuated OGD-induced apoptosis of PC-12 cells compared with the OGD and OGD 

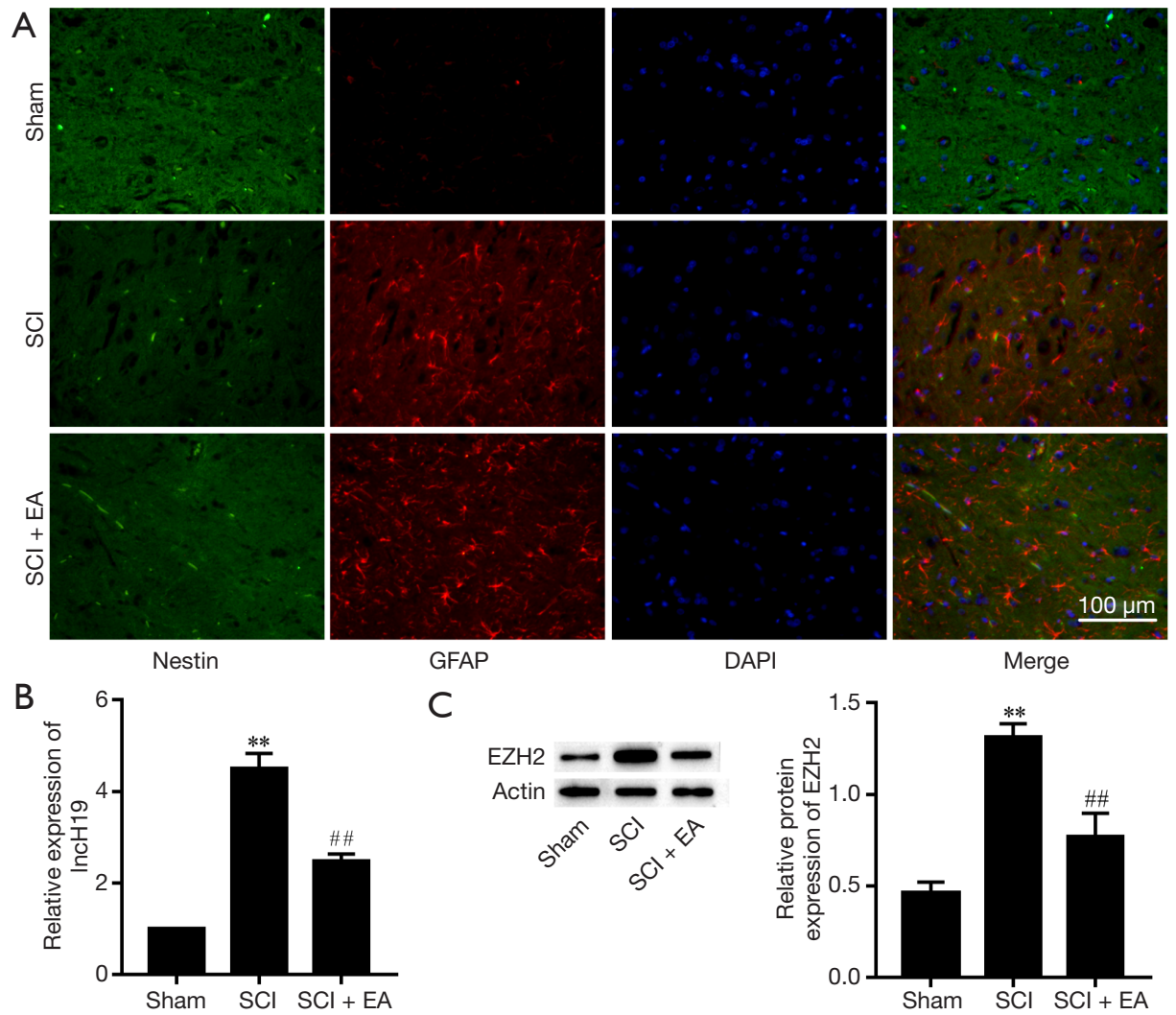

GFAP

DAPI

Merge

C
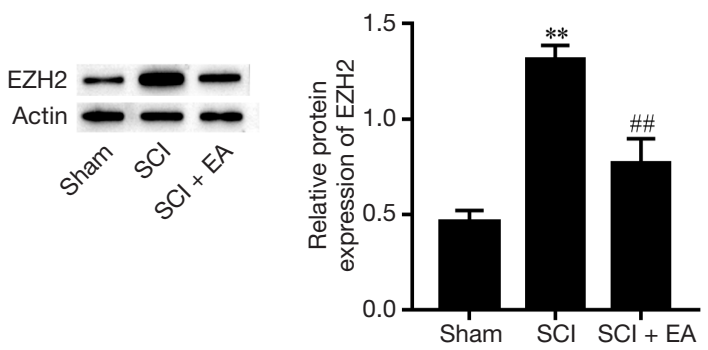

Figure 1 EA inhibits the expression of H19 and EZH2 in the injured spinal cords of rats. (A) The expression of GFAP and nestin protein in the spinal cord tissues of SCI or EA-treated rats was detected by immunofluorescence staining. Red represents GFAP positivity, green represents nestin positivity, and blue (DAPI) represents nuclei. (B) The expression levels of H19 in rat spinal cord tissues were measured by RT-qPCR. (C) The expression levels of EZH2 protein in rat spinal cord tissues were detected by western blot. ${ }^{* *} \mathrm{P}<0.01$ compared with sham group; ${ }^{\#} \mathrm{P}<0.01$ compared with SCI group. SCI, spinal cord injury; EA, electroacupuncture; GFAP, glial fibrillary acidic protein; DAPI, 4',6-diamidino-2-phenylindole; RT-qPCR, real-time quantitative polymerase chain reaction.

+ si-NC groups (Figure 2B), and alleviated OGD-induced inhibition of cell viability (Figure 2C). Moreover, the protein expression levels of Notch-related factors were significantly decreased in the OGD + si-H19 group (Figure 2D). The above results evidenced that suppression of H19 inhibited the Notch signaling pathway and OGD-induced injury in PC-12 cells.

\section{Suppression H19 decreased OGD-induced cell injury by downregulating EZH2}

To further explore the role of H19 in SCI, we examined its relationship with EZH2 expression. As shown in Figure $3 A, B$, the expression levels of $\mathrm{H} 19$ and EZH2 were significantly increased by OGD treatment; these effects were reversed by knockdown of H19, but EZH2 expression was ultimately restored by EZH2 overexpression/.
These observations indicated that EZH2 was positively regulated by H19. Moreover, the viability of PC-12 cells was decreased after OGD treatment but increased after interference of $\mathrm{H} 19$, and cell viability was terminally repressed by EZH2 overexpression (Figure 3C). OGD treatment also elevated cell apoptosis, and this effect was reversed by $\mathrm{H} 19$ suppression but was finally boosted by overexpressing EZH2 (Figure 3D). These results showed that suppression of $\mathrm{H} 19$ could alleviate OGD-induced injury in PC-12 cells via the downregulation of EZH2.

\section{Suppression of EZH2 alleviated OGD-induced cell injury by inbibiting the Notch signaling pathway}

To determine whether suppression of EZH2 alleviates OGD-induced cell injury, we suppressed EZH2 activation 

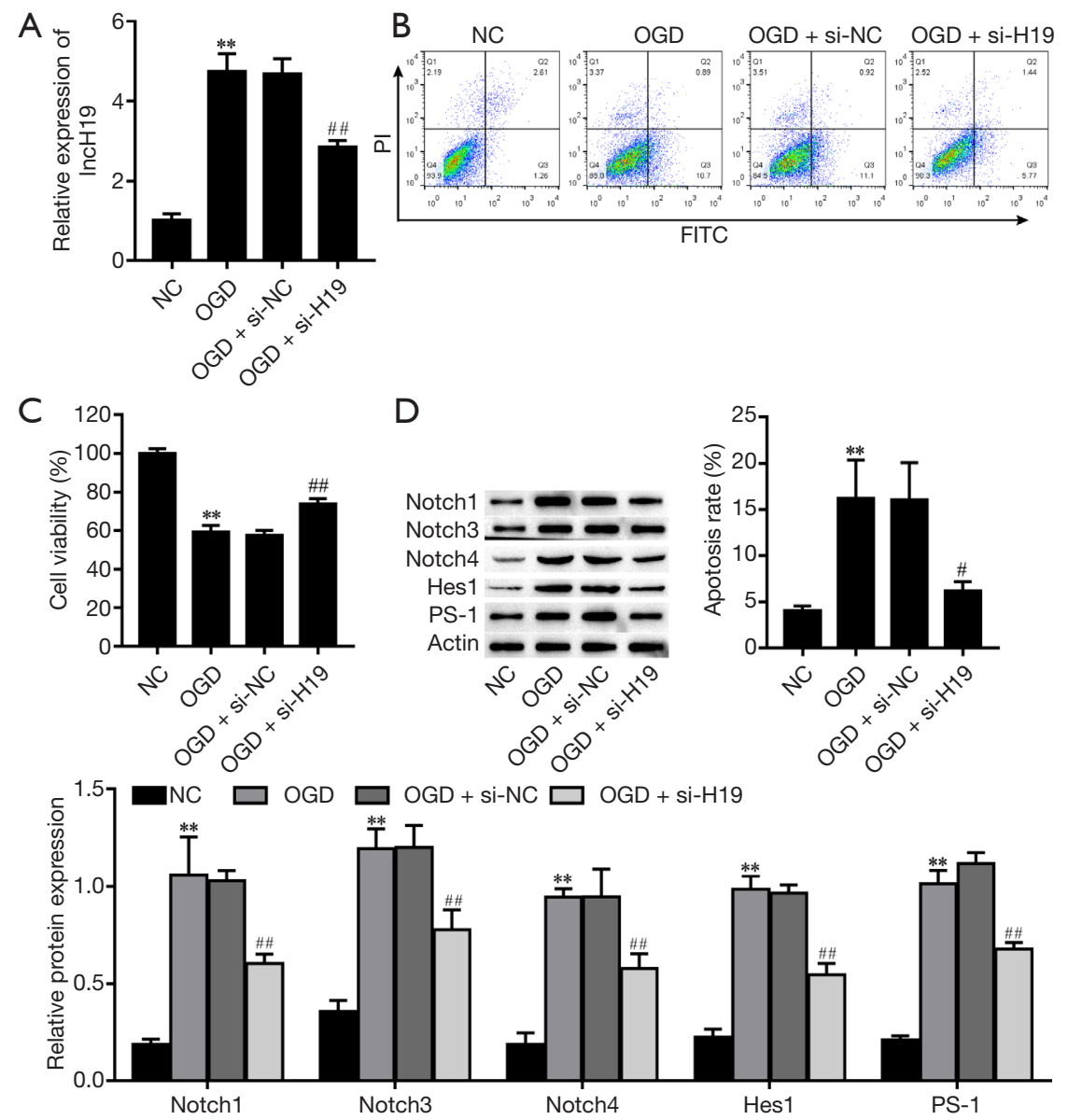

Figure 2 Suppression of H19 inhibits the Notch signaling pathway and OGD-treated PC-12 cell injury. (A) H19 expression was measured by RT-qPCR. (B) Cell apoptosis was evaluated by flow cytometry. (C) Cell viability was measured by Cell Counting Kit-8 assay. (D) The protein expression levels of Notch-related factors were measured by western blot. ${ }^{* *} \mathrm{P}<0.01$ compared with $\mathrm{NCs}$; $\mathrm{P}<0.05$ compared with OGD group; ${ }^{\#} \mathrm{P}<0.01$ compared with OGD group. NC, negative control; OGD, oxygen-glucose deprivation; PI, propidium iodide; FITC, fluorescein isothiocyanate; RT-qPCR, real-time quantitative polymerase chain reaction.

using the EZH2 inhibitor GSK126 (24,41). As Figure 4A,B show, GSK126 markedly alleviated OGD-induced cell apoptosis and elevated cell viability. Next, we investigated whether EZH2 is a regulator of the Notch signaling pathway. We found that OGD treatment upregulated the expression of Notch-related factors, but the Notch signaling pathway was inhibited by GSK126 (Figure 4C). Our results indicated that $\mathrm{EZH} 2$ regulates $\mathrm{PC}-12$ cell viability and apoptosis by inhibiting the Notch signaling pathway.

\section{Suppression of $\mathrm{H19}$ alleviated OGD-induced cell injury through inbibition of the EZH2/Notch axis}

Next, the effects of the H19/EZH2/Notch signaling pathway on OGD-induced cell injury were investigated.
The results showed that OGD treatment elevated H19 expression, which was reversed by interference of $\mathrm{H} 19$, while H19 expression was not altered by overexpression of EZH2 or GSK126 (Figure 5A). The expression of EZH2 was inhibited by interference of $\mathrm{H} 19$, which was reversed by EZH2 overexpression, while GSK126 did not alter H19 expression (Figure 5B). OGD treatment induced the activation of the Notch signaling pathway; this effect was reversed by suppressing GSK126 or H19, but the Notch signaling pathway was finally activated by EZH2 overexpression (Figure 5C). These results indicated that H19 regulates the Notch signaling pathway through EZH2. Next, we investigated whether the H19/EZH2/Notch axis regulates the apoptosis and viability of OGD-treated PC12 cells. We found that PC-12 cell apoptosis was promoted 
A
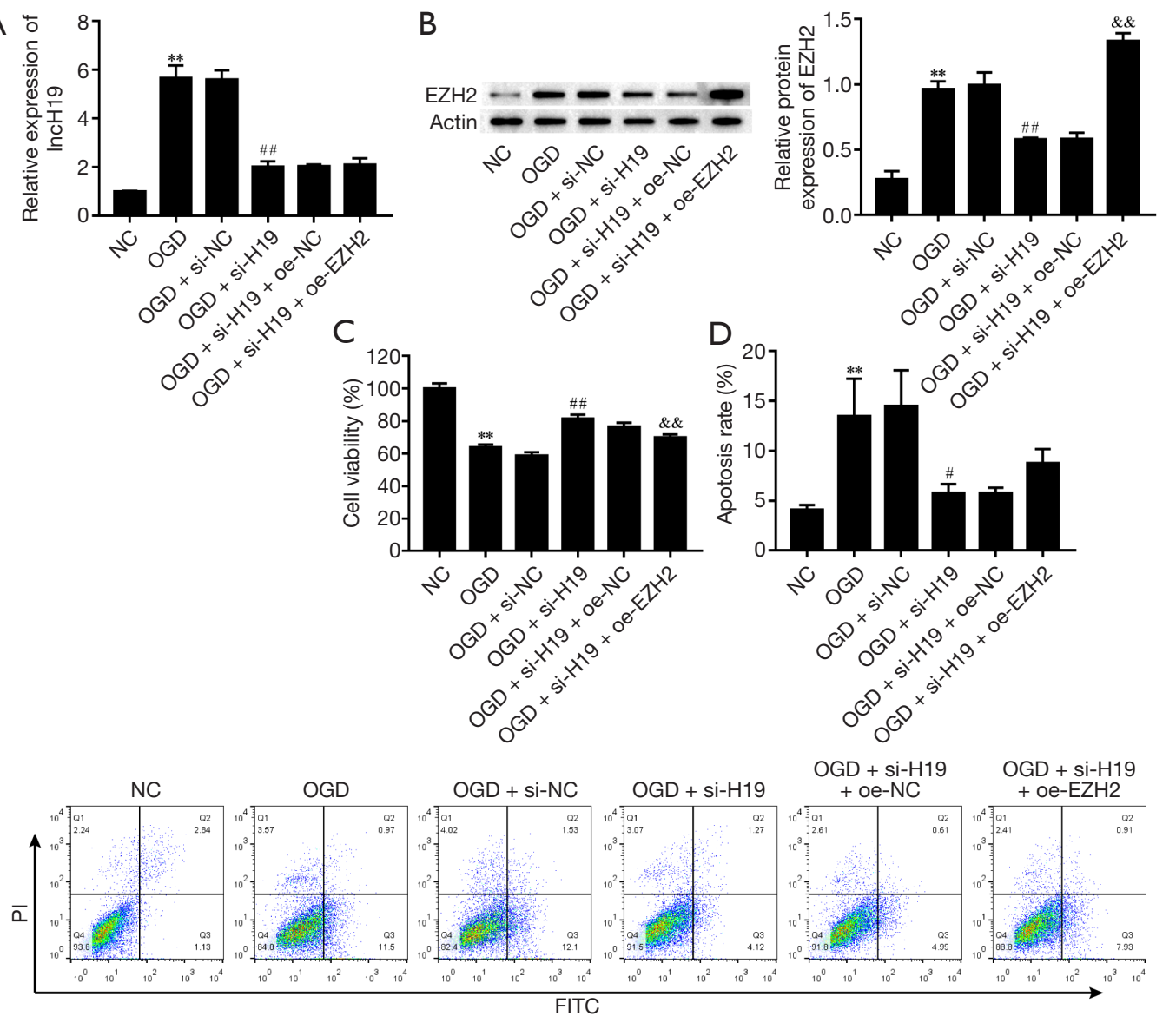

Figure 3 Suppression of H19 decreases OGD-induced cell injury by downregulating EZH2. (A) Expression levels of H19 were measured by RT-qPCR. (B) EZH2 protein levels were measured by western blot. (C) Cell viability was measured by Cell Counting Kit-8 assay. (D) Cell apoptosis was evaluated by flow cytometry. ${ }^{* *} \mathrm{P}<0.01$ compared with $\mathrm{NCs} ;{ }^{*} \mathrm{P}<0.05$ compared with OGD group; ${ }^{* \#} \mathrm{P}<0.01$ compared with OGD group; ${ }^{\& \&} \mathrm{P}<0.01$ compared with OGD + si-H19 group. NC, negative control; OGD, oxygen-glucose deprivation; PI, propidium iodide; FITC, fluorescein isothiocyanate; RT-qPCR, real-time quantitative polymerase chain reaction.

by OGD treatment but was inhibited by GSK126 or H19 interference, and cell apoptosis was ultimately boosted by EZH2 overexpression (Figure 6A). Cell viability was inhibited by OGD treatment but was enhanced by the downregulation of H19 or GSK126, and cell viability was terminally repressed by EZH2 upregulation (Figure 6B). These results indicated that inhibition of $\mathrm{H} 19$ alleviated OGD-induced cell injury through suppression of the EZH2/Notch signaling pathway.

\section{EA promoted the recovery of rats with SCI by suppressing the Notch signaling pathway via the H19/EZH2 axis}

Next, we validated the influence of EA on the expression of H19/EZH2 and Notch-related factors in vivo. We found that SCI elevated H19 expression, and EA reversed this effect; however, H19 expression was ultimately boosted by overexpression of H19 (Figure 7A). SCI upregulated EZH2 expression; this effect was reversed with EA, but EZH2 expression was finally boosted by H19 overexpression (Figure $7 B$ ). Our previous study found that EA inhibits the Notch signaling pathway (12); therefore, we next explored the effects of EA on this pathway in SCI rats. The results indicated that EA inhibited the Notch signaling pathway, which was reversed by overexpression of H19 (Figure 7C). These results suggested that EA inhibits the Notch signaling pathway in SCI rats by downregulating the H19/ EZH2 axis.

In our previous study, EA was observed to improve SCI in rats (12). Therefore, in the present research, we further 

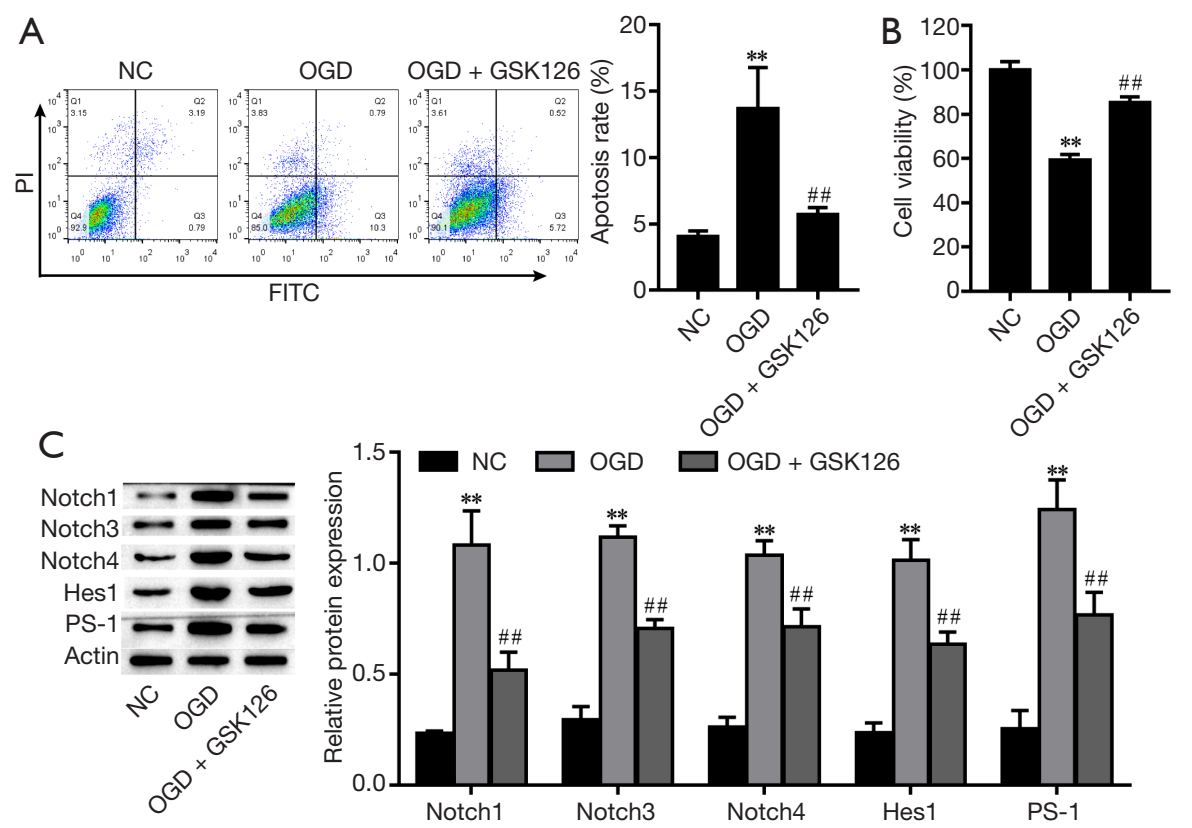

Figure 4 Suppression of EZH2 alleviates OGD-induced cell injury by inhibiting the Notch signaling pathway. (A) Cell apoptosis was evaluated by flow cytometry. (B) Cell viability was examined by Cell Counting Kit-8 assay. (C) The protein expression levels of Notchrelated factors were measured by western blot. ${ }^{* *} \mathrm{P}<0.01$ compared with $\mathrm{NCs} ;{ }^{\# \#} \mathrm{P}<0.01$ compared with OGD group. NC, negative control; OGD, oxygen-glucose deprivation; PI, propidium iodide; FITC, fluorescein isothiocyanate.

explored whether EA alleviates SCI in rats by modulating H19/EZH2. As shown in Figure 8A, the survival rates in the SCI, SCI + EA, SCI + EA + Lenti-H19, and SCI + EA + Lenti-NC groups were significantly lower than that in the control group. Furthermore, the SCI + EA and SCI + $\mathrm{EA}+$ Lenti-NC groups showed superior survival to both the SCI and SCI + EA + Lenti-H19 groups. The body weight and Basso-Beattie-Bresnahan (BBB) score in the SCI, SCI + EA, SCI + EA + Lenti-H19, and SCI + EA + Lenti-NC groups were significantly lower than that in the control group. Furthermore, the SCI + EA and SCI + EA + Lenti-NC groups showed superior body weight and BBB score to both the SCI and SCI + EA + Lenti-H19 groups (Figure 8B,C). In our experiment, the levels of GFAP protein were significantly elevated after SCI but were reduced by EA; however, they were ultimately boosted by overexpression of H19 (Figure 8D). In contrast, the levels of nestin protein were reduced by SCI; this effect was reversed after EA, but the levels of nestin protein were terminally repressed by H19 overexpression. These data indicated that EA promotes the recovery of SCI rats, and increases NSC proliferation and differentiation by suppressing the H19/EZH2/Notch axis.

\section{Discussion}

SCI is an irremediable condition following which the potential for structural repair and functional recovery is poor. There is evidence suggesting that EA can protect or prevent the death of functional neurons during the early and middle stages of SCI, inhibit the Notch signaling pathway, and promote NSC proliferation $(12,42)$. SCI is followed by an acute but long-lasting inflammatory response, and marked by increase in reactive oxygen species production $(43,44)$. Previous studies found that apolipoprotein E (ApoE) has anti-inflammatory, antioxidant and anti-apoptotic properties in SCI (45). Dai et al. found that EA reduces SCI inflammation and oxi-dative stress reactions by increasing ApoE expression (46). Additionally, EA stimulation induces neuroprotective effects after SCI correlated with the up-regulation of brain-derived neurotrophic factor and neurotrophin-3 (47). Notably, a recent study reported that $\mathrm{EA}+$ Schwann cell transplantation can improve the locomotor function in SCI rats, which may be related to its effects in reducing the immune rejecting reaction (48). Emerging studies have shown that EA can inhibit the induction and transmission of pain signals 


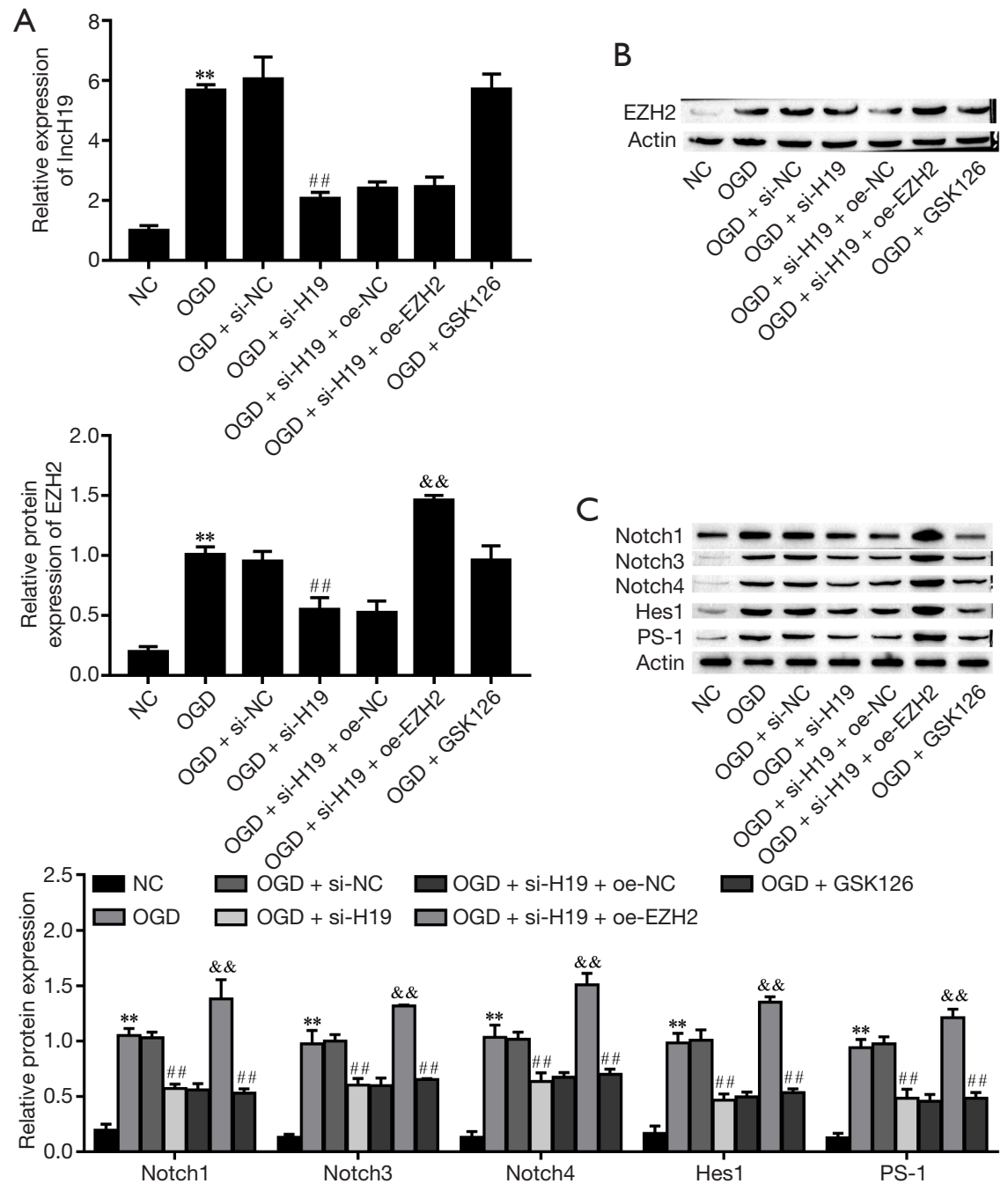

Figure 5 Suppression of H19 inhibits OGD-induced Notch signaling pathway activation via downregulation of EZH2. (A) H19 expression levels were determined by RT-qPCR. (B,C) The protein expression levels of Notch-related factors were measured by western blot. ** $\mathrm{P}<0.01$ compared with NCs; ${ }^{\# \#} \mathrm{P}<0.01$ compared with OGD group; ${ }^{\& \&} \mathrm{P}<0.01$ compared with OGD + si-H19 group. NC, negative control; OGD, oxygen-glucose deprivation; RT-qPCR, real-time quantitative polymerase chain reaction.

and, consequently, mediate anti-nociceptive and antiinflammatory effects by rebalancing the neural-immuneendocrine interactions (49). The above research shows that EA can promote the recovery of locomotor in SCI. Therefore, illuminating and understanding the regulatory mechanism of EA in promoting the repair of SCI is vital to the discovery of novel and effective strategies for clinical intervention.

LncRNAs function in a wide range of biological processes including the regulation of nervous system diseases. Previous research has shown lncRNAs may play an important role in the early immuno-inflammatory response after SCI (29). H19 expression has been well established to be upregulated in SCI $(29,33)$. In the current research, we also found that H19 expression was upregulated in both SCI rats (Figure $1 B$ ) and OGD-treated PC-12 cells (Figure 2A). The overexpression of $\mathrm{H} 19$ might accelerate cerebral ischemia and reperfusion injury as well as induce the apoptosis of hippocampal neuronal and PC-12 cells $(32,50,51)$. Interestingly, we found that EA suppressed H19 expression and promoted the repair of SCI (Figure 1B), and silencing of $\mathrm{H} 19$ significantly attenuated OGD-induced 

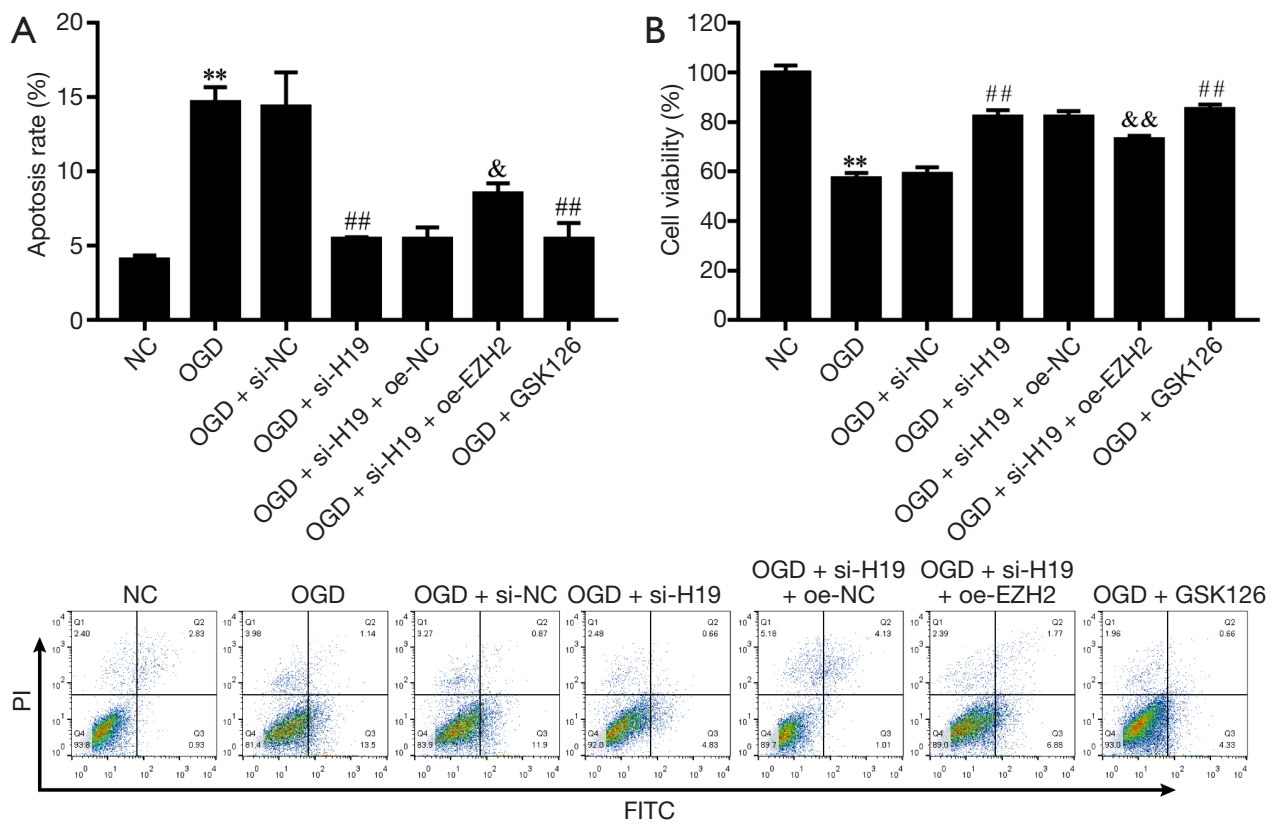

Figure 6 Suppression of H19 alleviates OGD-induced cell injury through down-regulating EZH2. (A) Cell apoptosis was evaluated by flow cytometry. (B) Cell viability was examined by Cell Counting Kit- 8 assay. ${ }^{* *} \mathrm{P}<0.01$ compared with $\mathrm{NCs}$; ${ }^{\# \#} \mathrm{P}<0.01$ compared with OGD group; ${ }^{\circledR} \mathrm{P}<0.01$ compared with OGD + si-H19 group; ${ }^{\&} \mathrm{P}<0.01$ compared with OGD + si-H19 group. NC, negative control; OGD, oxygen-glucose deprivation; PI, propidium iodide; FITC, fluorescein isothiocyanate.

injury in PC-12 cells (Figure 2B). These observations suggest that downregulation of H19 by EA may be associated with the repair of SCI (51). The results of this study emphasize the function of $\mathrm{H} 19$ as a participant in SCI and its progression, thus evidencing the potential of $\mathrm{H} 19$ as a novel target for SCI treatment.

Our study further showed that EZH2 expression was upregulated in SCI rats (Figure $1 C$ ) and OGDtreated PC-12 cells (Figure 3B), and that EZH2 inhibitor significantly attenuated OGD-induced injury in PC-12 cells (Figure $4 A, B$ ). Notably, EZH2 plays a critical role in cell proliferation and apoptosis. In hair follicle stem cells, for instance, EZH2 promotes cell proliferation and differentiation by repressing miR-22 (23), which increases apoptosis and proinflammatory cytokine release by activating STAT3 (22). A recent study reported that H19 regulates EZH2 expression through its interaction with miR-138 (52). Also, Hong et al. found that H19 interacts with EZH2 to regulate gene expression $(22,35)$. Therefore, it was hypothesized that H19 may serve as a factor to regulate or recruit EZH2. However, we confirmed that EA and silencing of $\mathrm{H} 19$ also significantly decreased EZH2 expression (Figure 1C,3B). Taken together, these data strongly suggest that $\mathrm{H} 19$ is a functional molecule that regulates EZH2 expression in SCI.

Previous research has shown that SCI activates the Notch signaling pathway whereas EA suppresses the Notch signaling pathway (12). Studies have also put H19 forward as an important functional factor involved in the maintenance of the Notch signaling pathway in the cell proliferation and apoptosis processes (30). Our results suggest that H19 plays a role in elevating the gene expression of factors by activating the Notch signaling pathway (Figure 2D). Wasson et al. revealed a critical role of EZH2 in the Notch signaling pathway (25), and Zheng et al. showed that EZH2 directly binds to the Notch1 promoter to regulate Notch1 expression (53). Here, we found that EZH2 inhibitor suppressed the Notch signaling pathway (Figure 4C), and we dissected this phenomenon further, demonstrating that EZH2 expression is driven by H19 and is linked to the activation of the Notch signaling pathway. Interestingly, Wasson et al. reported that EZH2 regulates the Notch signaling pathway via miR-34a; however, Zheng et al. found that EZH2 regulates Notch signaling by promoting the transcription of this pathway $(25,53)$. Nevertheless, how EZH2 regulates the Notch signaling pathway is still unclear 
A

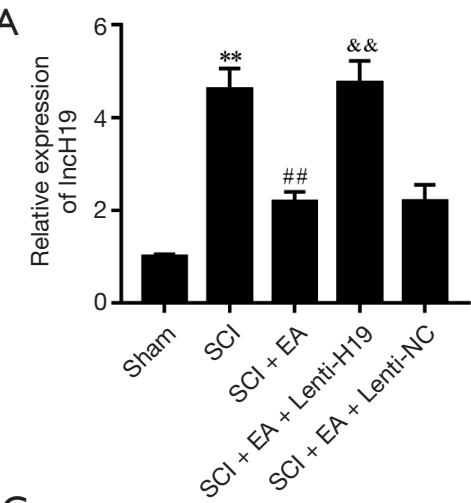

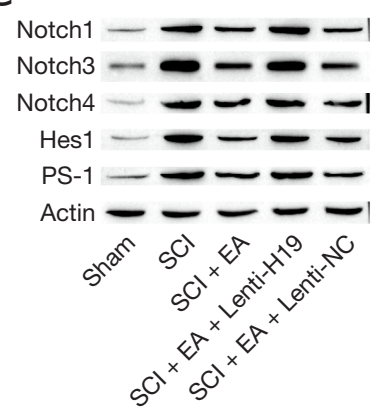

B

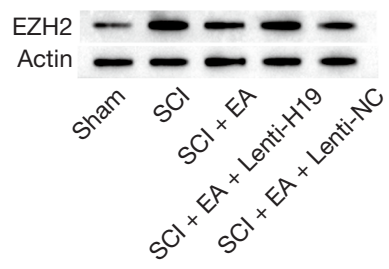

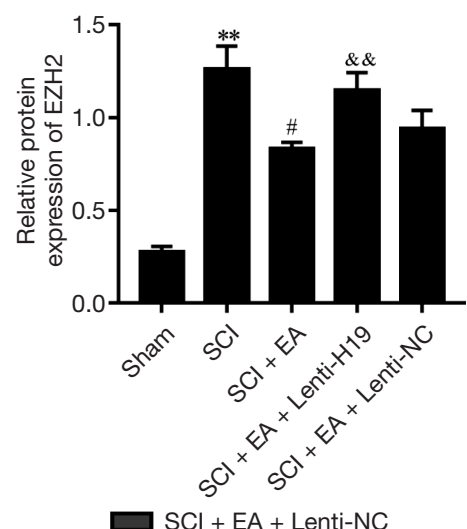

2.0
은 $\quad \begin{array}{ll}\text { Sham } & \text { SCl + EA } \\ \text { SCl } & \square S C l+E A+\text { Lenti-H19 }\end{array}$

$\mathrm{SCl}+\mathrm{EA}+$ Lenti-NC

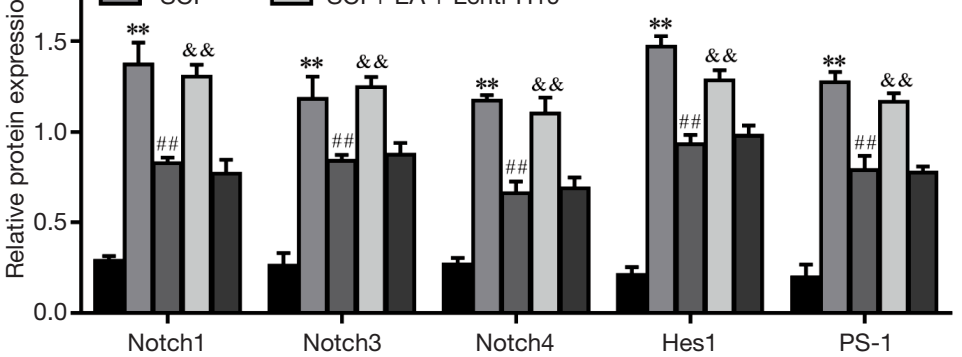

Figure 7 EA inhibits the Notch signaling pathway via the H19/EZH2 axis. (A) H19 expression levels were determined by RT-qPCR. (B,C) The protein expression levels of Notch-related factors were measured by western blot. ${ }^{* *} \mathrm{P}<0.01$ compared with sham group; ${ }^{\#} \mathrm{P}<0.01$ compared with sham group; ${ }^{\# \#} \mathrm{P}<0.01$ compared with SCI group; ${ }^{\& \&} \mathrm{P}<0.01$ compared with SCI + EA group. SCI, spinal cord injury; EA, electroacupuncture; NC, negative control; lenti, lentiviral; RT-qPCR, real-time quantitative polymerase chain reaction.

and requires further study.

Our results further demonstrated that the H19/EZH2/ Notch axis might be a novel target for clinical intervention in SCI. A recent study showed that H19 knockdown effectively relieved Ischemia-reperfusion—or OGD/R-induced neuronal cell oxidative stress and apoptosis (54). In our study, we showed that H19 suppression alleviated OGD-induced PC-12 cell injury (Figures 5 and 6), while overexpression of $\mathrm{H} 19$ reversed the effects of EA in improving SCI in rats by upregulating the EZH2/Notch signaling pathway (Figures 7 and 8). In addition, it has been reported that lipopolysaccharide treatment could significantly increase GFAP expression, while H19 knockdown decreased the protein content of GFAP (55). Our results showed that overexpression of H19 increased the expression of GFAP while decreasing that of nestin (Figure 8D). These observations demonstrate that H19 is a novel target for protecting against SCI. Thus, targeting the H19/EZH2/Notch axis could serve as a novel strategy for clinical intervention for patients with SCI. We previous research shown that EA inhibits neuronal apoptosis, astrocytes differentiation, and Notch signaling activation, and accelerate edema and inflammation reduction and neural function repair (12). In this study, we found that EA inhibited neuronal apoptosis, astrocytes differentiation and Notch signaling activation, and accelerate neural function repair by inhibiting H19/EZH2 axis. These results provide an important experimental reference for EA in the repair of SCI.

It has been shown that EA stimulation at 2 and $50 \mathrm{~Hz}$ showed continuous and significant enhancement in their motor performance, but $100 \mathrm{~Hz}$ exhibited a notice-able but not significant improvement in locomotor activity (56). Our studies found EA stimulation at $2 \mathrm{~Hz}$ promoted NSC proliferation (Figure 1A) (12). Zhu et al. found EA $(60 \mathrm{~Hz}$ for $1.05 \mathrm{~s}$ and $2 \mathrm{~Hz}$ for $2.85 \mathrm{~s}$ alternately) stimulation also promotes NSC proliferation (57), suggestion different waveform electric acupuncture has the similar effect. Our studies found EA promoted NSC proliferation by inhibiting Notch signaling pathway (Figures 7 and 8), suggesting inhibition of Notch signaling pathway would as a target to protect NSC apoptosis of SCI. Accoumulating 

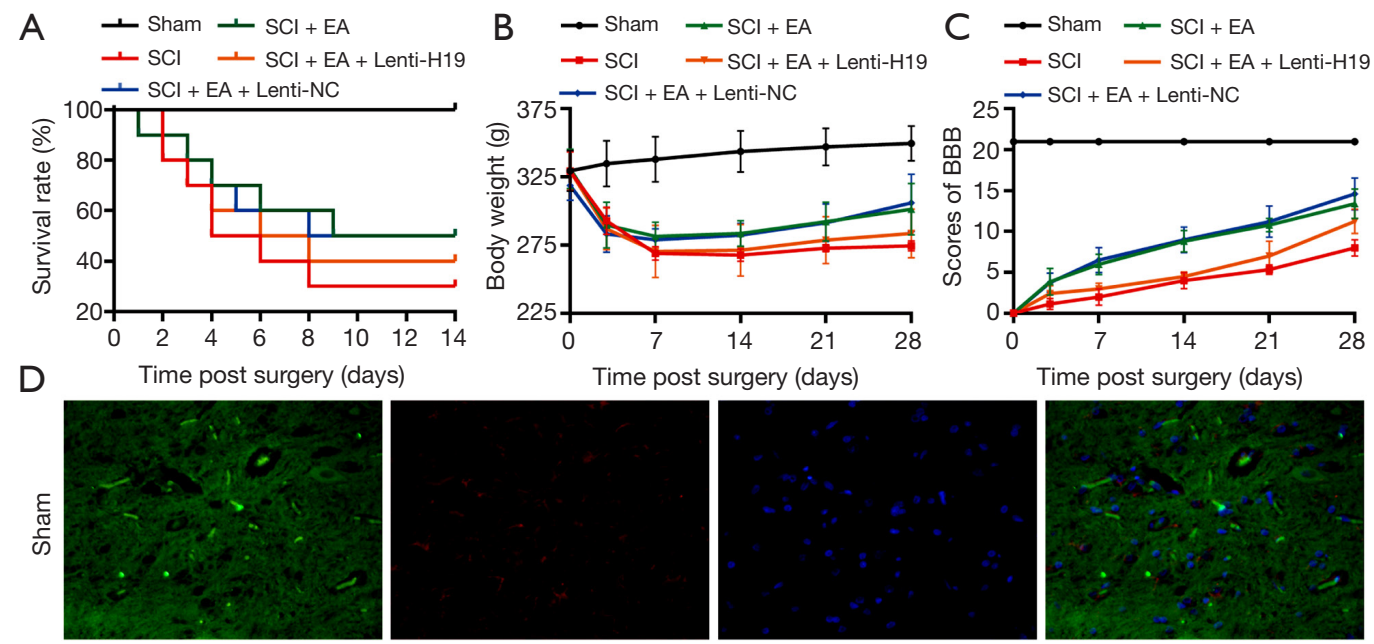

ime post surgery (days)
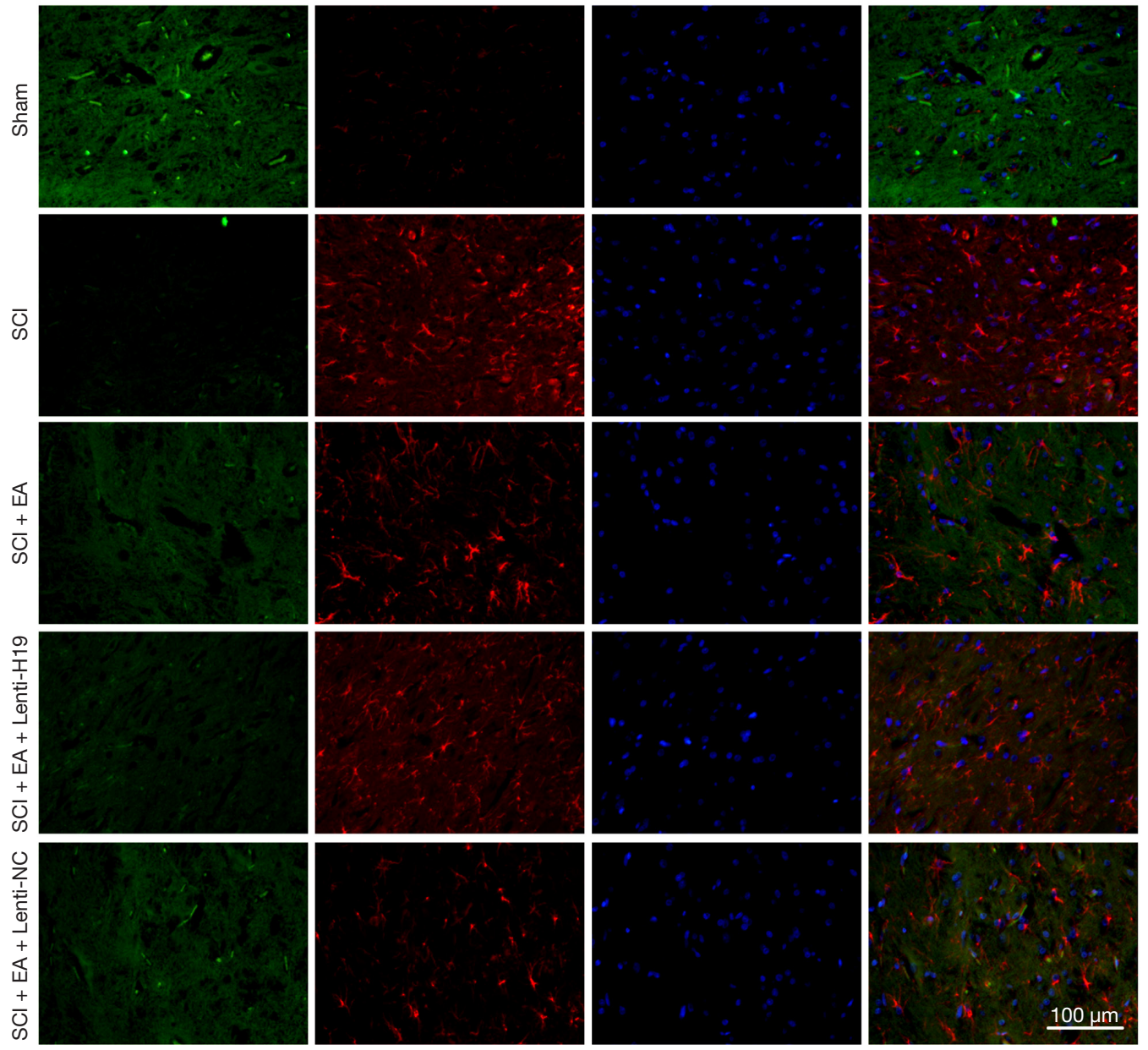

Nestin
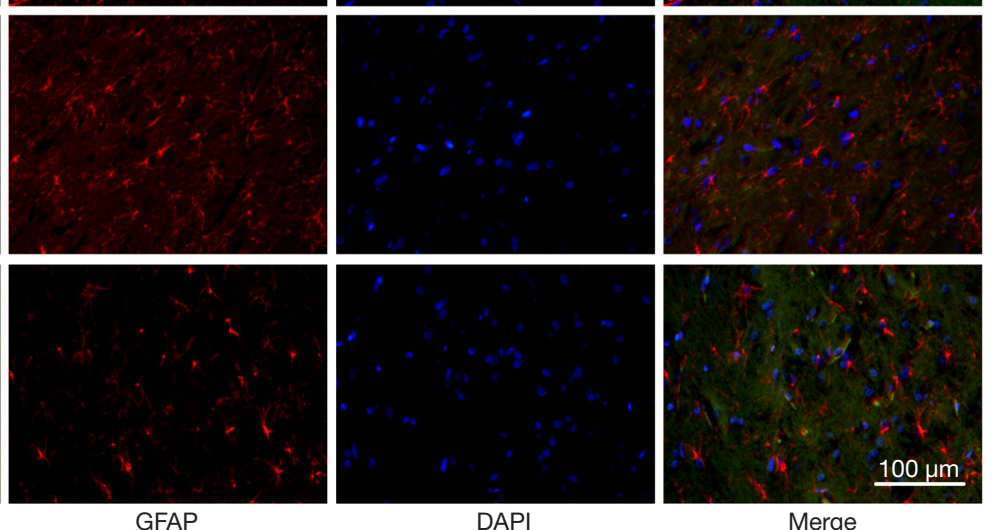

Figure 8 EA promotes the recovery of SCI rats via the H19/EZH2 axis. (A) Survival curves changes at 1, 3, 7, 14, 21, and 28 days after SCI. (B) Body weight changes at 1, 3, 7, 14, 21, and 28 days after surgery. (C) BBB scores at 1, 3, 7, 14, 21, and 28 days after surgery. (D) The protein expression levels of GFAP and nestin were detected by immunofluorescence staining. Red shows GFAP positivity, green shows nestin positivity, and blue (DAPI) shows nuclei. EA, electroacupuncture; SCI, spinal cord injury; BBB, Basso-Beattie-Bresnahan; GFAP, glial fibrillary acidic protein; DAPI, 4',6-diamidino-2-phenylindole.

evidence shows that inhibition of Notch signaling pathway can improve SCI, including $\gamma$-secretase blocker (58), resveratrol (59), and sodium tanshinone IIA silate (60). Our data support the idea that EA-mediated Notch signaling pathway activation in SCI.

In conclusion, we have demonstrated that EA suppresses H19 expression in SCI rats and H19 plays an important role in the repair of SCI via the EZH2/Notch signaling 
pathway. Our findings reveal that $\mathrm{H} 19$ is involved in the pathophysiology of SCI, which may shed light on the design of therapeutic strategies for SCI.

\section{Acknowledgments}

Funding: This work was supported by Associated Project of Yunnan Province Science \& Technology Department and Kunming Medical University Basic Research for Application (2017FE467 (-032)), Yunnan Health Training Project of High Level Talents (H-2018054), sub-project of the Special Fund for Applied Basic Research of The Center for Diagnosis and Treatment of Neurological Diseases in Yunnan Province (ZX2019-03-05), and PhD Research Fund of the First Aiffliated Hospital of Kunming Medical University (2020BS019).

\section{Footnote}

Reporting Checklist: The authors have completed the ARRIVE reporting checklist. Available at http://dx.doi. org/10.21037/atm-21-1526

Data Sharing Statement: Available at http://dx.doi. org/10.21037/atm-21-1526

Conflicts of Interest: All authors have completed the ICMJE uniform disclosure form (available at http://dx.doi. org/10.21037/atm-21-1526). The authors have no conflicts of interest to declare.

Ethical Statement: The authors are accountable for all aspects of the work in ensuring that questions related to the accuracy or integrity of any part of the work are appropriately investigated and resolved. All animal experiments were performed in accordance with the guidelines for animal care and approved by the Institutional Animal Care and Use Committee at Kunming Medical University (No. 2020-158).

Open Access Statement: This is an Open Access article distributed in accordance with the Creative Commons Attribution-NonCommercial-NoDerivs 4.0 International License (CC BY-NC-ND 4.0), which permits the noncommercial replication and distribution of the article with the strict proviso that no changes or edits are made and the original work is properly cited (including links to both the formal publication through the relevant DOI and the license).
See: https://creativecommons.org/licenses/by-nc-nd/4.0/.

\section{References}

1. Hulsebosch CE. Recent advances in pathophysiology and treatment of spinal cord injury. Adv Physiol Educ 2002;26:238-55.

2. Biering-Sørensen B, Kristensen IB, Kjr M, et al. Muscle after spinal cord injury. Muscle Nerve 2009;40:499-519.

3. Dudley-Javoroski S, Shields RK. Muscle and bone plasticity after spinal cord injury: Review of adaptations to disuse and to electrical muscle stimulation. J Rehabil Res Dev 2008;45:283-96.

4. Hulsebosch CE. From discovery to clinical trials: Treatment strategies for central neuropathic pain after spinal cord injury. Curr Pharm Des 2005;11:1411-20.

5. Qin W, Bauman WA Cardozo C. Bone and muscle loss after spinal cord injury: organ interactions. Ann N Y Acad Sci 2010;1211:p.66-84.

6. Tran AP, Warren PM, Silver J. The biology of regeneration failure and success after spinal cord injury. Physiol Rev 2018;98:881-917.

7. Ahuja CS, Fehlings M. Concise review: Bridging the gap: Novel neuroregenerative and neuroprotective strategies in spinal cord injury. Stem Cells Transl Med 2016;5:914-24.

8. Lu P, Jones LL, Tuszynski MH. Axon regeneration through scars and into sites of chronic spinal cord injury. Exp Neurol 2007;203:8-21.

9. Sun F, Lin CG, Dana M, et al. Effects of axon degeneration on oligodendrocyte lineage cells: Dorsal rhizotomy evokes a repair response while axon degeneration rostral to spinal contusion induces both repair and apoptosis. Glia 2010;58:1304-19.

10. Ohri SS, Maddie MA, Zhao Y, et al. Attenuating the endoplasmic reticulum stress response improves functional recovery after spinal cord injury. Glia 2011;59:1489-502.

11. Suh H, Consiglio A, Ray J, et al. Cell stem cell article in vivo fate analysis reveals the multipotent and selfrenewal capacities of Sox $2+$ neural stem cells in the adult hippocampus. Cell Stem Cell 2007;1:515-28.

12. Geng X, Sun T, Li J, et al. Electroacupuncture in the repair of spinal cord injury: inhibiting the Notch signaling pathway and promoting neural stem cell proliferation. Neural regen res 2015;10:394-403.

13. Arvidsson A, Collin T, Kirik D, et al. Neuronal replacement from endogenous precursors in the adult brain after stroke. Nature Medicine 2002;8:963-70.

14. Parent JM, Vexler ZS, Chao G, et al. Rat forebrain 
neurogenesis and striatal neuron replacement after focal stroke. Ann Neurol 2002;52:802-13.

15. Alexson TO, Hitoshi S, Coles BL, et al. Notch signaling is required to maintain all neural stem cell populations-irrespective of spatial or temporal niche. Dev Neurosci 2006;28:34-48.

16. Obermair FJ, Schroter A Thallmair M. Endogenous neural progenitor cells as therapeutic target after spinal cord injury. Physiology 2008;23:296-304.

17. Wang G, Cao P, Fan Y, et al. Emerging roles of HSF1 in cancer: Cellular and molecular episodes. Biochim Biophys Acta Rev Cancer 2020;1874:188390.

18. Han B, Li T, Zheng S. MicroRNA-133b aggravates atherosclerosis by activating the Notch signaling pathway. Mol Med Rep 2020;22:1621-30.

19. Zhang S, Botchway BOA, Zhang Y, et al. Resveratrol can inhibit Notch signaling pathway to improve spinal cord injury. Ann Anat 2019;223:100-7.

20. Wu Z, Liu H, Sun W, et al: RNF180 mediates STAT3 activity by regulating the expression of RhoC via the proteasomal pathway in gastric cancer cells. Cell Death Dis 2020;11:881.

21. Zhou Z, Tian X, Mo H, et al. Adipose mesenchymal stem cell transplantation alleviates spinal cord injury-induced neuroinflammation partly by suppressing the Jagged1/ Notch pathway. Stem Cell Res Ther 2020;11:212.

22. Wang J, Li P, Xu X, et al. MicroRNA-200a inhibits inflammation and atherosclerotic lesion formation by disrupting EZH2-mediated methylation of STAT3. Front Immunol 2020;11:907.

23. Cai B, Li M, Zheng Y, et al. EZH2-mediated inhibition of microRNA-22 promotes differentiation of hair follicle stem cells by elevating STK40 expression. Aging 2020;12:12726-39.

24. Tsou PS, Campbell P, Amin MA, et al. Inhibition of EZH2 prevents fibrosis and restores normal angiogenesis in scleroderma. Proc Natl Acad Sci U S A 2019;116:3695-702.

25. Wasson CW, Abignano G, Hermes H, et al. Long non-coding RNA HOTAIR drives EZH2-dependent myofibroblast activation in systemic sclerosis through miRNA 34a-dependent activation of NOTCH. Ann Rheum Dis 2020;79:507-17.

26. Hyunjoo K, Kyoungsub S, Han C, et al. Epigenetic silencing of miRNA-34a in human cholangiocarcinoma via EZH2 and DNA methylation: Impact on regulation of Notch pathway. Ame J pathol 2017;187:2288-99.

27. Fatica A, Bozzoni I. Long non-coding RNAs: new players in cell differentiation and development. Nat Rev Genet
2014;15:7-21.

28. Harries, Lorna W. Long non-coding RNAs and human disease. Biochem Soc Trans 2012;40:902-6.

29. Ding L, Fu WJ, Di HY, et al. Expression of long noncoding RNAs in complete transection spinal cord injury: a transcriptomic analysis. Neural Regen Res 2020;15:1560-7.

30. Zhi LQ, Zhong Q, Ma JB, et al. LncRNA H19 inhibitor represses synovial cell proliferation and apoptosis in rats with rheumatoid arthritis via Notch signaling pathway. Eur Rev Med Pharmacol Sci 2020;24:4088-94.

31. Han CL, Ge M, Liu YP, et al. Long non-coding RNA H19 contributes to apoptosis of hippocampal neurons by inhibiting let-7b in a rat model of temporal lobe epilepsy. Cell Death Dis 2018;9:617.

32. Zhao YH, Ji TF, Luo Q, et al. Long non-coding RNA H19 induces hippocampal neuronal apoptosis via Wnt signaling in a streptozotocin-induced rat model of diabetes mellitus. Oncotarget 2017;8:64827-39.

33. Diao Y, Ma Q, Cui F, et al. Human umbilical cord mesenchymal stem cells: osteogenesis in vivo as seed cells for bone tissue engineering. J Biomed Mater Res A 2009;91:123-31.

34. Zhang DM, Lin ZY, Yang ZH, et al. IncRNA H19 promotes tongue squamous cell carcinoma progression through $\beta$-catenin/GSK3 $\beta /$ EMT signaling via association with EZH2. Am J Transl Res 2017;9:3474-86.

35. Yuan Z, Bian Y, Ma X, et al. LncRNA H19 knockdown in human amniotic mesenchymal stem cells suppresses angiogenesis by associating with $\mathrm{EZH} 2$ and activating vasohibin-1. Stem Cells Dev 2019;28:781-90.

36. Poon PC, Gupta D, Shoichet MS, et al. Clip compression model is useful for thoracic spinal cord injuries. Spine 2007;32:2853-9.

37. Rice T, Larsen J, Rivest S, et al. Characterization of the early neuroinflammation after spinal cord injury in mice. J Neuropathol Exp Neurol 2007;66:184-95.

38. Gong ZM, Tang ZY, Sun XL. MiR-411 suppresses acute spinal cord injury via downregulation of Fas ligand in rats. Biochem Biophys Res Commun 2018;501:501-6.

39. Livak KJ, Schmittgen TD. Analysis of relative gene expression data using real-time quantitative PCR and the 2(-Delta Delta C(T)) Method. Methods 2001;25:402-8.

40. Ji XC, Dang YY, Gao HY, et al. Local injection of lenti$\mathrm{BDNF}$ at the lesion site promotes M2 macrophage polarization and inhibits inflammatory response after spinal cord injury in mice. Cell Mol Neurobiol 2015;35:881-90.

41. Michael TM, Heidi MO, Gopinath G, et al. EZH2 inhibition as a therapeutic strategy for lymphoma with 
EZH2-activating mutations. Nature 2012;492:108-12.

42. Mekhail M, Almazan G, Tabrizian M. Oligodendrocyteprotection and remyelination post-spinal cord injuries: A review. Prog Neurobiol 2012;96:322-39.

43. Zhang N, Yin Y, Xu SJ, et al. Inflammation \& apoptosis in spinal cord injury. Indian J Med Res 2012;135:287-96.

44. Bains M, Hall ED. Antioxidant therapies in traumatic brain and spinal cord injury. Biochim Biophys Acta 2012;1822:675-84.

45. Seitz A, Kragol M, Aglow E, et al. Apolipoprotein E expression after spinal cord injury in the mouse. J Neurosci Res 2003;71:417-26.

46. Dai N, Huang SQ, Tang CL, et al. Electroacupuncture improves locomotor function by regulating expression of inflammation and oxidative stress-related proteins in mice with spinal cord injury. Zhen Ci Yan Jiu 2019;44:781-6.

47. Tu WZ, Jiang SH, Zhang L, et al. Electro-acupuncture at Governor Vessel improves neurological function in rats with spinal cord injury. Chin J Integr Med 2017. doi: 10.1007/s11655-017-2968-9. [Epub ahead of print].

48. Tan CF, Huang SQ, Tang CL, et al. Effect of electroacupuncture combined with Schwann cell transplantation on limb locomotor ability, regional remyelination and expression of spinal CD4 and CD8 proteins in compressive spinal injury rats. Zhen Ci Yan Jiu 2019;44:391-8.

49. Li Y, Yang M, Wu F, et al. Mechanism of electroacupuncture on inflammatory pain: neural-immuneendocrine interactions. J Tradit Chin Med 2019;39:740-9.

50. Huang J, Yang J, Li J, et al. Association of long noncoding RNA H19 polymorphisms with the susceptibility and clinical features of ischemic stroke in southern Chinese Han population. Metab Brain Dis 2019;34:1011-21.

51. Hu S, Zheng J, Du Z, et al. Knock down of lncRNA H19 promotes axon sprouting and functional recovery after cerebral ischemic stroke. Brain Res 2020;1732:146681.

Cite this article as: Geng X, Zou Y, Li S, Qi R, Jing C, Ding X, $\mathrm{Li}$ J, Yu H. Electroacupuncture promotes the recovery of rats with spinal cord injury by suppressing the Notch signaling pathway via the H19/EZH2 axis. Ann Transl Med 2021;9(10):844. doi: $10.21037 /$ atm-21-1526
52. Hong $\mathrm{Y}, \mathrm{He} \mathrm{H}$, Wen $\mathrm{S}$, et al. Long noncoding RNAH19 promotes cell proliferation and invasion by acting as a ceRNA of miR138 and releasing EZH2 in oral squamous cell carcinoma. Int J Oncol 2018;52:901-12.

53. Zheng X, Pang B, Gu G, et al. Melatonin inhibits glioblastoma stem-like cells through suppression of EZH2NOTCH1 signaling axis. Int J Biol Sci 2017;13: 245-53.

54. Gao N, Tang H, Gao L, et al. LncRNA H19 aggravates cerebral ischemia/reperfusion injury by functioning as a ceRNA for miR-19a-3p to target PTEN. Neuroscience 2020;437:117-29.

55. Li P, Li Y, Dai Y, et al. The LncRNA H19/miR-1$3 \mathrm{p} / \mathrm{CCL} 2$ axis modulates lipopolysaccharide (LPS) stimulation-induced normal human astrocyte proliferation and activation. Cytokine 2020;131:155106.

56. Escobar-Corona C, Torres-Castillo S, Rodríguez-Torres $\mathrm{EE}$, et al. Electroacupuncture improves gait locomotion, H-reflex and ventral root potentials of spinal compression injured rats. Brain Res Bull 2017;131:7-17.

57. Zhu Y, Wu Y, Zhang R. Electro-acupuncture promotes the proliferation of neural stem cells and the survival of neurons by downregulating miR-449a in rat with spinal cord injury. Excli J 2017;16:363-74.

58. Qian D, Li L, Rong Y, et al. Blocking Notch signal pathway suppresses the activation of neurotoxic A1 astrocytes after spinal cord injury. Cell Cycle 2019;18:3010-29.

59. Zhang S, Botchway BOA, Zhang Y, et al. Resveratrol can inhibit Notch signaling pathway to improve spinal cord injury. Ann Anat 2019;223:100-7.

60. Li X, Luo D, Hou Y, et al. Sodium Tanshinone IIA Silate Exerts Microcirculation Protective Effects against Spinal Cord Injury In Vitro and In Vivo. Oxid Med Cell Longev 2020;2020:3949575.

(English Language Editor: J. Reynolds) 